\title{
Examples and Non-examples as a Road to Understanding the Concept of Function
}

\author{
Eka Resti Wulan1, Yulia Izza El Milla² \\ 1 IAIN Kediri, Kediri, Indonesia \\ 2 STKIP PGRI Lumajang, Lumajang, Indonesia
}

"Corresponding author: Ngronggo, Kediri City, East Java, 64127, Indonesia. e-mail addresses: ekaresti.wulan @iainkediri.ac.id

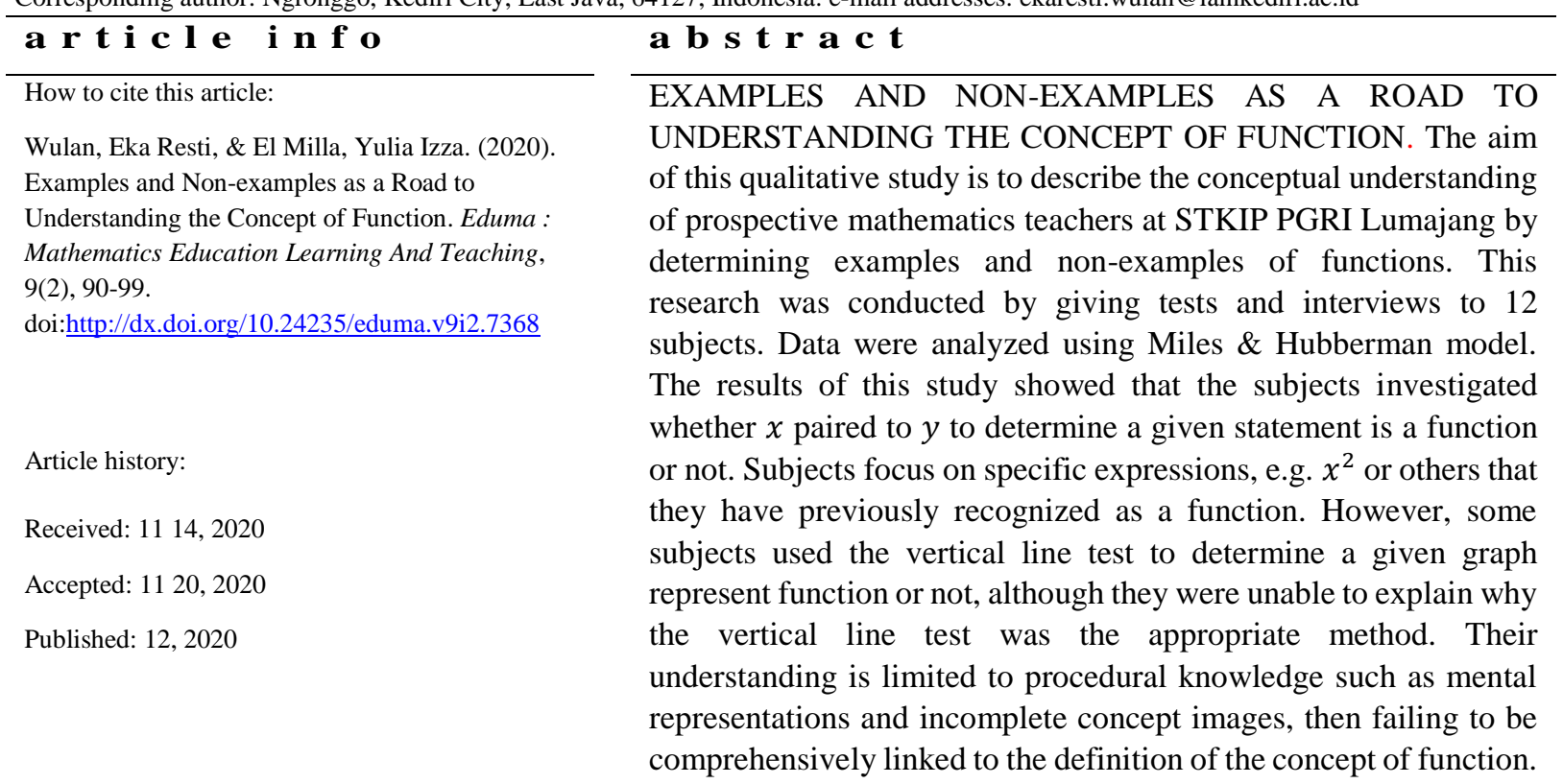




\section{INTRODUCTION}

The concept in mathematics started from defined and undefined terms, then developed into postulates and theorems. The definition includes general conditions that are not limited to specific examples. It can be accepted mathematically, and very crucial in mathematics learning (Fujita \& Jones, 2006; Zazkis \& Leikin, 2008), then to learn a specific definition we have to understand the notations and symbols used (Ekayanti, 2018). The concept of understanding is important to achieve meaningful learning (Noto et al., 2020) and fundamental ability to solve problems, either mathematical problems or close related problems in other fields (Radiusman, 2020). Concepts in mathematics are interrelated each other as well as real life, includes the concept of function (Bardini, et al., 2014; Güçler \& Heather, 2015).

For decades, the definition of a function was closely tied to its geometric representation. In 1692, Leibniz (Bardini, et al., 2013) for the first time introduced the term of "function" with the aspects of curves and gradients at a point. Furthermore, Newton (Bardini, et al., 2013) defined a function as a variable related to a "smooth" curve, described as points that move along the curve. In the 18th century, "function" was used to describe an expression formed from variables and several constants. In 1748, Euler (Bardini, et al., 2013) expressed his thoughts on functions, and stated that if a quantity depends on the previous quantity, the quantity changes if the previously quantity changed, then the quantity is called a function of the previous quantity.

In the $19^{\text {th }}$ century, the "new" concept of function developed until the early $20^{\text {th }}$ century. The discussion of functions led to
Bourbaki's definition (Bardini, et al., 2013), namely sequential pair relations where the first element form a pair with the second uniquely. The Bourbaki's definition is often referred to as the Dirichlet-Bourbaki definition. Kleiner (Bardini, et al., 2013) concluded that based on its history, the concept of function is described in two versions, namely by using mental representations of geometry and algebraic expressions.

A solid understanding of the concept of function is a prerequisite for studying various branches of mathematics, such as calculus (Bardini, et al., 2013; Hagen, 2015; Larue \& Engelke, 2015). The function concept also has sizable portion in the secondary school curriculum (Bardini, et al., 2013; Bardini, et al., 2014; Carlson et al., 2002; Gagatsis, et al., 2006). However, many undergraduate students of mathematics have a weak understanding of functions, then raising difficulties when studying topics involve functions. This lack of understanding and misconceptions experienced by students are not easy to fix because it becomes their belief in the initial knowledge. It makes them experience distrust to their own thoughts (Bardini, dkk., 2014).

Killpatrick, et al. (Long, 2005) divide understanding into two, conceptual understanding and procedural understanding. Conceptual understanding reflects to someone's ability in reasoning a condition that need to be careful about applying definition, relations, or representations of certain concepts (NCTM, 2000). Conceptual understanding allows one to apply and adapt some mathematical ideas that can be used in new situations. On the other hand, Hope said that procedural understanding is an ability that focuses on skills and step-bystep procedures without explicit reference 
to mathematical ideas (Ghazali \& Zakaria, 2011). Understanding the concept of function is not a procedural understanding, but conceptual understanding. In Bloom's taxonomy, understanding is at the second in a cognitive level. At the level of understanding, someone must interpret the basic understanding of a concept, provide examples, classify, conclude, simplify, compare, and explain (Forehand, 2005).

Although understanding the concept of function has been widely carried out in many researchs, there are still facts that prospective mathematics teachers do not have sufficient understanding of function (Bardini, et al., 2013; Bardini, et al., 2014). They have mastered skills, without being completed by conceptual knowledge (Bardini, et al., 2014). We had observed at prospective mathematics teachers' document at STKIP PGRI Lumajang, there were students found could not determine that a given representation was a function or not. Prospective teacher reflected meanings and representations of function about involving correspondence/ dependence relationships and also those based the idea of a "machine"/formula/rule (Oldham et al., 2020).

In other hand, function is a mathematical knowledge involving different ways of representing the concept, by means of numerical table and algebraic notation (Ribeiro \& da Ponte, 2019). Therefore the examples and non-examples of function in various way must be has a role in learning function's concept. Thus, research on an understanding of the knowledge of functions through example and nonexamples possessed by prospective teachers of mathematics is highly desirable. How they understand the definition of function is important because as prospective teachers, they are required to know the concept of function correctly before the concept is taught to students later. Then become a facilitator to be able to guide students to gain experience in reshaping the definition of function, teachers must have the ability to be involved in the process such that the knowledge the teacher has, become an important prerequisite for the success of their students (Fujita \& Jones, 2006; Zazkis \& Leikin, 2008). Appropriate teaching of the concept is therefore very important (Oldham et al., 2020) and teacher knowledge plays an important role in shaping teaching quality (Fujita \& Jones, 2006).

\section{METHODS}

This research described students' understanding of the concept of function, namely categorizing a given statement as a function or not. Thus, the approach used was a qualitative approach with descriptive research. Researchers acted as the main instrument because researchers are planners of research, designers of method, then the method implementers, data collectors, data analyzers, conclusion drawers, and report generators (Creswell, 2015, Creswell \& Creswell, 2017).

The subjects in this study were students of the prospective Mathematics Teacher Programme of STKIP PGRI Lumajang in the first to fourth years of 206 students. Data obtained through tests and interviews. The interview subjects were determined based on the analysis of the subject's statement regarding the definition of the function they know. We had 12 subjects interviewed, but based on the reduction of data interview reduction; we used only 10 subjects. The test consisted of 10 items, of which 6 items asked the subject to categorize the rules as 
either example or not function examples. The other 4 items asked the subject to categorize the given graph. The type of test was closed-question in form "Yes or No" problem. Data consistency was checked by the triangulation method, especially comparing the result from different collection methods (Cohen et al., 2007; Creswell, 2015).

We used data analysis techniques include: (1) reduction data, (2) display data, and (3) drawing conclusions or verification (Miles \& Hubberman, 1994). The process of selecting, focusing, simplifying, abstracting, data transforming, and coding was carried out when reducting data from test and interview result. The reduction result were presented in a form of organized matrix. Drawing conclusions were based on indepth observations of the regularity of response patterns, the explanation of the interviews, the emerged data structures, the causal relationships, and the propositions of the displayed data.

\section{RESULT AND DISCUSSION}

The instrument test were given to 206 students of the prospective mathematics teacher programme of STKIP PGRI Lumajang. Based on the test result of subjects reducted into 169 students because of the result of the other was not good and uninformative.

Overall, the subjects who can answer the questions correctly are $49,15 \%$. It means that half of all students of the prospective mathematics teacher programme of STKIP PGRI Lumajang are still unable to categorize functions and not functions. Surprisingly, there was no a single student that can answer all the questions correctly.
3. For all $x \in \mathbb{R}, f(x)= \begin{cases}2 x, & \text { if } x \geq 0 \\ 2, & \text { if } 0<x<1 \\ x^{2}, & \text { if } x<0\end{cases}$

4. For all $x \in \mathbb{R}$,

$$
f(x)=\left\{\begin{array}{cc}
2 x+7, & \text { if } x>2 \\
-3 x+8, & \text { if } x<1
\end{array}\right.
$$

Figure 1. Question 3 and Question 4 about function in hybrid

In questions 3 and 4 about determining the hybrid function (piecewise) as in Figure 1, there were $12 \%$ of the subjects who originally answered the hybrid function as not a function/did not answer question number 3, but answered as a function in question number 4. Another fact, the ratio's subjects that can answer question number 4 as not a function is about onefifth of the total subjects. This shows inconsistency in students' understanding of functions. It is possible that the understanding of the definition of the function failed, namely that each member of the domain must have exactly one/single partner on the codomain.

Based on the 12 students had been interviewed, only $10 \%$ could answer question number 4 correctly. This was exacerbated by the reasons stated by the subject are not suitable with the concept of function. The subject stated he could not represent a graph portraying the expression in question 4, such that he answered with unsure that the given rule was not a function. This finding supports the failure of students to connect the mathematical ideas related to the concept of function. Even though the idea of the concept of function is expanded with various variations at the college level, one of which is with various forms of domains and codomains (Bardini, et al., 2014).

In question 5 about determining a rule in the form of a sentence, as in Figure 2, 
almost half of all students can not answer correctly. Even in question 6, only a third of all students answered correctly. Based on the interview result, only 3 out of 10 interviewed subjects answered question number 5 correctly. It is not good by the fact that the correct answer is not accompanied by acceptable logical reasoning. The interview process showed the subject US could not imagine the graph that was formed, while the subject UA tried to find the rules formed from the given expression. The unclear reasons expressed by the two interviewed subjects reflect the subject's inability to determine a graph or representation of function's rules (Bardini, et al., 2014).

5. Suppose $f$ os a function with rule $f(s)$ is the area of circle with $x$ as circumference.

6. Suppose $f$ os a function with rule $f(s)$ is the area of rectangle with $x$ as perimeter.

Figure 2. Question 5 and Question 6 about a rule in sentences

All the interviewed subjects stated that they were not familiar with descriptive rules such as in questions 5 and 6 . Subjects tended not to understand the meaning described, encountered unfamiliar shapes, and tended to use the vertical line test in questions number 5 and 6 . In this data, we were unable to see the correct answer to question number 5 and question number 6 together. Suppose it is possible to see that both are correct. It that case, it means that the student is able to understand that the function can be described in mathematical words and also recognizes that a rectangular unit of the area will not show the singularity of its circumference (Bardini, et al., 2014).

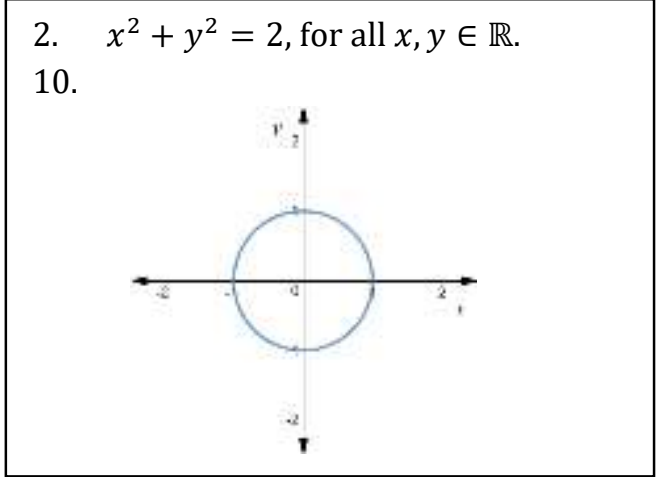

Figure 3. Question 2 and Question 10 about circle

In problems 2 and 10 as in Figure 3, they both represent a circle. Half of the students marked question number 2 as a function, but nearly a quarter marked question number 10 . This shows the inconsistency of student knowledge about the circles and its graphs. Students' tendency to use the vertical line test made them being more able to answer question number 10 correctly. The interviews with the subjects showed that they answered question number 10 as not an example of a function based on the results of the vertical line test. The subject did not do any further reasoning on question number 2 . The subject only remembers that the expression contains $y^{2}$ and the equation contains $f(x)$ or $y$. They experience confusion when a function is described in a form includes an "equal sign" but not expressed in a common function formula that they often encountered. The ambiguity of using equations in the function formula is the cause of the difficulty for students to use the equal sign as meaning in showing a relationship between two variable quantities and a similarity statement for two expressions (Oehrtman, et al., 2008). 


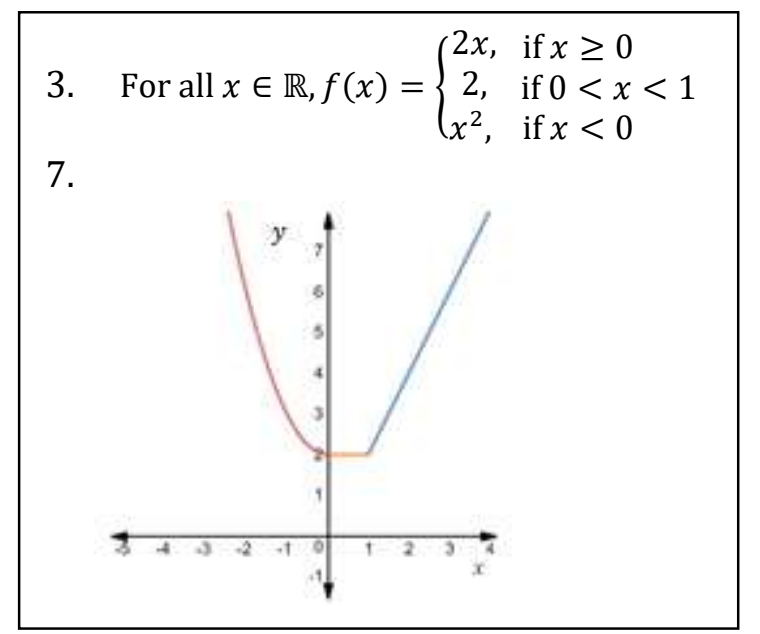

Figure 4. Question 3 and Question 7 about hybrid function

In questions 3 and 7, as in Figure 4, there was inconsistency about $10 \%$ of subjects that experienced answering the given hybrid as a function. The interview result of the subject US indicated that the reason for the inconsistency was the memory that the hybrid function about a rule, not represents a graph. This showed that the understanding of student functions in the form of a graph was not consistent. Unlike US, the subject ID stated that question 3 was a function. Subject ID reasoned in each part of the domain, exemplified by special points (not in general), exactly one partner was obtained in the codomain. However, in question number 7 the ID subject answered was not accompanied by the same reasoning. It is different from the understanding of students in general who assess that a hybrid function is two separate functions or even not a function (Vinner \& Dreyfus, 1989; Oehrtman, et al., 2008).

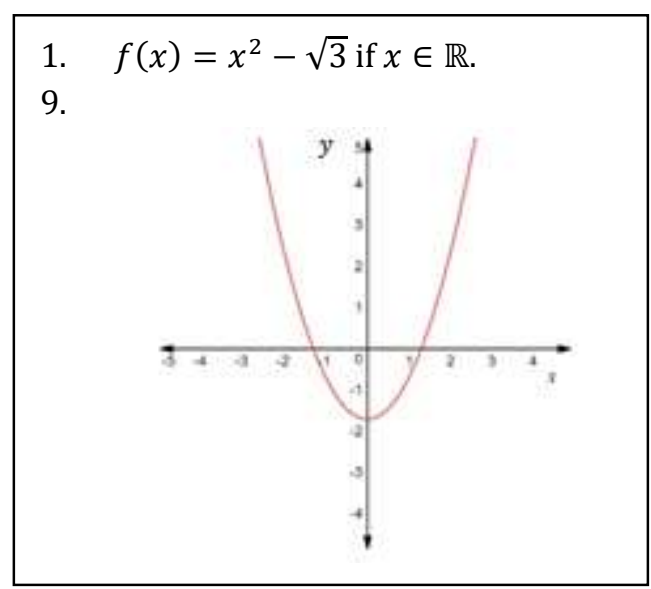

Figure 5. Question 1 and Question 9 about quadratic function

In question number 8 , as in Figure 6 , it is found that no more than a quarter of the total students answered correctly. This shows that most students still lack understanding of the vertical line test. Based on the results of 12 interviewed students, only two were able to correctly explain that based on the vertical line test result, there were two intersection points obtained from the graph being tested. Even so, the subjects could not explain why if they cut at more than one point, the graph being tested was not a function. Subjects only relied on memory when they obtained the topic in lecture activities. The existence of the analytical expression in the form of a vertical line test is part of the students' internal representation about the function concept. Although their beliefs are stronger than the formal definition they have (Hitt, 1998). 


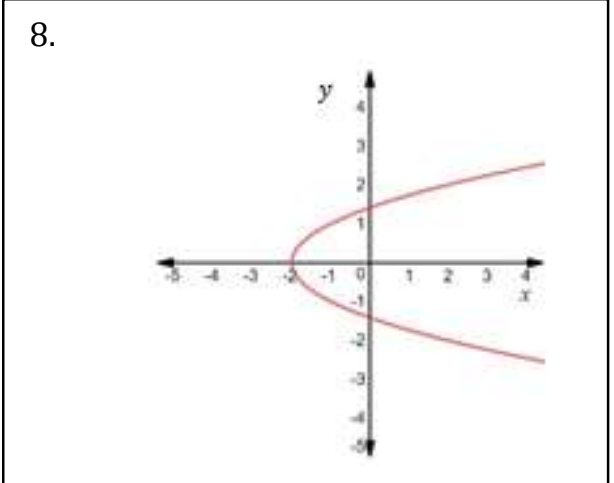

Figure 6. Question 8 about non-example of function

The research obtains a significant difference of correct answers, which is more than $30 \%$ of the total students. In contrast to Hitt (1998), the findings from the interview results showed that the subjects saw the graph of parabolic functions more often, but were not familiar with the graph of the hybrid function, especially the shape of the graph in question 7 was not a smooth curve. Graphs of functions that are not smooth are assessed as unfamiliarity so that students judge the graph as not representing a function (Vinner, 1983; Vinner \& Dreyfus, 1989)

The function concept definition stimulates the conceptual description of a rule or formula. For another, the graph or table values can serve as an illustration of the concept (concept images), which correspond to the definition of the concept (concept definition) (Panaoura et al., 2017). From the findings that have been described in the examples and new situations given, the subject only uses mental images in the form of memories or procedures that are carried out without significant reasoning relating to the conceptual description of functions, in the form of rules or graphics. This is because of the function definition which continues to evolve over time until it reaches the definition used currently (Bardini, et al.., 2013; Gagatsis, et al., 2006).

The existence of several approaches to the definition of a function, namely in geometry and algebra, creates its own difficulties for students in understanding the concept of functions. Visual representations or verbal explanations that precede formal definitions are also the cause of difficulties in learning the concept of function so that they have an impact on intuition, although intuition, visual representations, and verbal descriptions are also important in understanding a concept (Hitt, 1998; Kidron \& Picard, 2006). The image description of the actual function aims to clarify the concept may interfere with students' understanding of the formal definition of a function, so that students actually see the picture that they can easily understand as a function definition (Roh, 2008).

The strong emphasis on some of these findings is that subjects using procedures without understanding of this concept indepth. It is not useful in constructing a basic conception of function, which allows the use of a more meaningful interpretation of functions in various representational and new situations (Oehrtman, et al., 2008). Students cannot relate formal definitions to their mental images and they can use partial conceptual images with unsatisfactory conceptual understanding (Vinner \& Dreyfus, 1989). Students base their solutions on problemsolving tasks regarding concept definitions that may be true or may not be complete. The mismatch between the definition of the function that is studied by students caused by the nature of the task or the application of the concept of the function that they encounter, as well as the development of mathematical abilities which emphasizes procedural rather than 
conceptual abilities. That three things finally arises the difficulty of understanding the concept of function. (Bardini, et al., 2013; Gagatsis, et al., 2006; Hejnỳ et al., 2006).

\section{CONCLUSION AND IMPLICATION}

Almost half the number of prospective mathematics teacher of the STKIP PGRI Lumajang cannot categorize some expression whether it is functions or not. Especially, functions that are represented in the form of graphs and descriptions. They lack the understanding of function definition, that each member of the domain must have exactly one/single partner of codomains. Students' reasoning in determining functions and not functions only limited to mental images and incomplete conceptual images that fail to be comprehensively linked into the definition of the concept of function.

Various improvements are needed in instilling a conceptual understanding of the function definition. Meaningful learning is a key so that there are no leap conception experienced by students that cause misconceptions. For further research, it is necessary to study various lecture models emphasizing how a concept can be learned meaningfully by students, for example, such as exploratory learning involving examples and non-examples, both in real life and mathematical area.

\section{ACKNOWLEDGMENTS}

This research is funded by:

Direktorat Riset dan Pengabdian Masyarakat Direktorat Jenderal Penguatan Riset dan Pengembangan Kementerian Riset, Teknologi, dan Pendidikan Tinggi in accordance with the 2018 Fiscal Year Research Contract Number: 098 / SP2H / LT / K7 / KM / 2018;
February 26, 2018 between Kopertis Wilayah VII and STKIP PGRI Lumajang, Number SP DIPA-042.06.1.401516 / 2018 December 5, 2017

\section{REFERENCES}

Bardini, Caroline, Pierce, R., \& Vincent, J. (2013). First year university students' understanding of functions: Over a decade after the introduction of CAS in Australian high schools, what is new. Proceedings of the 9th DELTA Conference on Teaching and Learning of Undergraduate Mathematics and Statistics, 2-11.

Bardini, Caroline, Pierce, R., Vincent, J., \& King, D. (2014). Undergraduate Mathematics Students' Understanding of the Concept of Function. Indonesian Mathematical Society Journal on Mathematics Education, 5(2), 85-107.

Carlson, M., Jacobs, S., Coe, E., Larsen, S., \& Hsu, E. (2002). Applying covariational reasoning while modeling dynamic events: A framework and a study. Journal for Research in Mathematics Education, 352-378.

Cohen, L., Manion, L., \& Morrison, K. (2007). Research methods in education. London: Routledge.

Creswell, J. W. (2015). Educational research: Planning, conducting, and evaluating quantitative and qualitative research, enhanced pearson eText with loose-leaf version-access card package. Pearson Education, Inc.

Creswell, J. W., \& Creswell, J. D. (2017). Research design: Qualitative, quantitative, and mixed methods approaches. Sage publications. 
Ekayanti, A. (2018). Generalisasi teorema aproksimasi weierstrass. FIBONACCI: Jurnal Pendidikan Matematika Dan Matematika, 4(2), 105-112.

Forehand, M. (2005). Bloom's taxonomy: Original and revised. emerging perspectives on learning, teaching, and technology.

Fujita, T., \& Jones, K. (2006). Primary trainee teachers' understanding of basic geometrical figures in Scotland.

Gagatsis, A., Elia, I., Panaoura, A., Gravvani, K., \& Spyrou, P. (2006). An empirical four-dimensional model for the understanding of function. International Group for the Psychology of Mathematics Education, 137.

Ghazali, N. H. C., \& Zakaria, E. (2011). Students' procedural and conceptual understanding of mathematics. Australian Journal of Basic and Applied Sciences, 5(7), 684-691.

Güçler, B., \& Heather, T.-M. (2015). A Discursive Approach to Support Teachers' Development of Student Thinking About Functions. Proceedings of the 18th Annual Conference on Research in Undergraduate Mathematics Education, 562-567.

Hagen, C. (2015). Undergraduate Students' Understandings of Functions and Key Calculus Concepts. Proceedings of the 18th Annual Conference on Research in Undergraduate Mathematics Education. 574-580

Hejnỳ, M., Jirotková, D., \& Kratochvílová, J. (2006). Early conceptual thinking. International Group for the Psychology of Mathematics Education, 289.
Hitt, F. (1998). Difficulties in the articulation of different representations linked to the concept of function. The Journal of Mathematical Behavior, 17(1), 123134.

Kidron, I., \& Picard, T. D. (2006). Concept definition, concept image and the discrete-continuous interplay. International Group for the Psychology of Mathematics Education, 441.

Larue, R., \& Engelke, N. (2015). The Influence of Function and Variable on Students' Understanding of Calculus Optimization Problems. Proceedings of the 18th Annual Conference on Research in Undergraduate Mathematics Education, 673-677.

Long, C. (2005). Maths concepts in teaching: Procedural and conceptual knowledge. Pythagoras, 2005(62), 59-65.

NCTM (2000). Principles and standards for school mathematics (Vol. 1). Virginia: Key Curriculum Press.

Miles, M. B., Huberman, A. M., Huberman, M. A., \& Huberman, M. (1994). Qualitative data analysis: An expanded sourcebook. sage.

Noto, M. S., Pramuditya, S. A., \& Handayani, V. D. (2020). Exploration of Learning Obstacle Based on Mathematical Understanding of Algebra in Junior High School. Eduma: Mathematics Education Learning and Teaching, 9(1), https://doi.org/10.24235/eduma.v9i 1.5946

Oehrtman, M., Carlson, M., \& Thompson, P. W. (2008). Foundational reasoning abilities that promote coherence in students' function understanding. Making the 
Connection: Research and Teaching in Undergraduate Mathematics Education, 27, 42.

Oldham, E., Viseu, F., Martinho, M. H., Doggen, R., Price, E., \& Leite, L. (2020). Investigating prospective science and mathematics teachers' meanings for and representations of functions: An international study. http://repositorium.sdum.uminho.p t/

Panaoura, A., Michael-Chrysanthou, P., Gagatsis, A., Elia, I., \& Philippou, A. (2017). A structural model related to the understanding of the concept of function: Definition and problem solving. International Journal of Science and Mathematics Education, 15(4), 723-740.

Radiusman, R. (2020). Studi Literasi: Pemahaman Konsep Anak Pada Pembelajaran Matematika. FIBONACCI: Jurnal Pendidikan Matematika dan Matematika, 6(1), $1-8$.

https://doi.org/10.24853/fbc.6.1.1-8
Ribeiro, A. J., \& da Ponte, J. P. (2019). Professional learning opportunities in a practice-based teacher education programme about the concept of function. Acta Scientiae, 21(2), 49-74.

Roh, K. H. (2008). Students' images and their understanding of definitions of the limit of a sequence. Educational Studies in Mathematics, 69(3), 217-233.

Vinner, S. (1983). Concept definition, concept image and the notion of function. International Journal of Mathematical Education in Science and Technology, 14(3), 293-305.

Vinner, S., \& Dreyfus, T. (1989). Images and definitions for the concept of function. Journal for Research in Mathematics Education, 356-366.

Zazkis, R., \& Leikin, R. (2008). Exemplifying definitions: A case of a square. Educational Studies in Mathematics, 69(2), 131-148. 